\title{
Relacionamento Intergeracional, Práticas de Apoio e Cotidiano de Famílias de Crianças com Necessidades Especiais ${ }^{\mathbf{1}}$ Intergenerational Relationships, Support Practices and Daily Life of Families of Children With Special NeEDS
}

Thelma Simóes MATSUKURA ${ }^{2}$ Juliana Archiza YAMASHIRO ${ }^{3}$

RESUMO: o estudo exploratório, de abordagem qualitativa, objetivou investigar o relacionamento intergeracional e as práticas de apoio presentes no cotidiano de famílias de crianças com necessidades especiais. Participaram do estudo cinco máes, avós e irmãos mais velhos de crianças com deficiência, que responderam a roteiros de entrevistas semiestruturadas. As entrevistas foram analisadas qualitativamente por meio da técnica do Discurso do Sujeito Coletivo. Verificou-se que as avós apresentam-se como importante fonte de apoio à família ao dedicarem, inclusive, atençấo e cuidado ao irmão da criança com necessidades especiais. $\mathrm{O}$ estudo revela um relacionamento intergeracional positivo entre avós e netos. Destaca-se a necessidade de direcionar maior atenção especializada a esses membros da família e para a continuidade de investigação sobre o tema.

PALAVRAS-CHAVE: Educação Especial. Família. Atitude da Família. Crianças com necessidades especiais.

\begin{abstract}
This exploratory study based on a qualitative approach aimed to investigate intergenerational relationships and support practices in the daily lives of families of children with special needs. Study participants were five mothers, grandmothers and older siblings of children with disabilities, who answered a semi-structured interview guide. The interviews were analyzed qualitatively using the Collective Subject Discourse technique. It was found that grandmothers have been an important source of support for the family, because they are also concerned about devoting attention and care to the siblings of the child with disabilities. The study reveals a positive intergenerational relationship between grandmothers and grandchildren. The study highlights the need for directing more specialized attention to these family members and points out the need for further research on the subject.
\end{abstract}

KEYWORDS: Family. Intergenerational Relationship. Children with Special Needs.

\section{INTRODUÇÃo}

A família pode ser compreendida como um sistema constituído por vários níveis de relaçóes, composto por subsistemas, como marido-esposa, genitores-filhos, irmãosirmãos e avós-netos. Esse sistema interacional apresenta-se de maneira complexa, integrada e interdependente, cujas relaçóes se estabelecem a partir de mútua influência com o contexto sócio-histórico no qual estão inseridas, caracterizando uma rede cíclica de interações, de modo que se um dos membros muda de alguma maneira, essa mudança também afetará os demais (MINUCHIN; COLAPINTO; MINUCHIN, 1999; MINUCHIN; FISHMAN, 1990; TURNBULL; TURNBULL, 2001).

\footnotetext{
${ }^{1}$ Agradecimentos: As autoras agradecem às famílias participantes do estudo e à FAPESP, pelo financiamento.

${ }^{2}$ Terapeuta Ocupacional; Professora Associada do Departamento de Terapia Ocupacional da Universidade Federal de São Carlos; Docente do Programa de Pós Graduação em Terapia Ocupacional da Universidade Federal de São Carlos e do Programa de PósGraduação em Educação Especial da UFSCar. thelma@ufscar.br

${ }^{3}$ Terapeuta Ocupacional, mestranda do Programa de Pós-Graduação em Terapia Ocupacional da Universidade Federal de São Carlos - UFSCar. julianayamashiro@yahoo.com.br
} 
Todos esses relacionamentos aos quais a criança está exposta contribuem de maneira significativa para o desenvolvimento infantil (NUNES, 2006). Além disso, fatores microssistêmicos, como a qualidade das interaçóes e relaçóes entre os membros familiares e pessoas próximas, particularmente no que tange às práticas psicossociais de cuidados e de suporte implementados nesses contextos, associam-se na promoção de um desenvolvimento adequado e saudável da criança (ZAMBERLAN; BIASOLI-ALVES, 1996).

Segundo Araújo e Dias (2002) os relacionamentos intergeracionais entre avós e netos têm sido mais amplamente estudados a partir da década de 1980. Com isto, descobriu-se que, além de todos os benefícios que o relacionamento com os avós pode oferecer aos netos ao longo de seu desenvolvimento, essas crianças também são importante fonte de apoio e influência aos avós.

Nesta direçáo, quando se trata do nascimento de uma criança com necessidades especiais $^{4}$, essa realidade pode implicar em diferentes sentimentos e reaçóes nos membros da família e alterar a estrutura familiar estabelecida antes de seu nascimento (REICHMAN; CORMAN; NOONAN, 2008; SILVA; DESSEN, 2001).

Estudiosos da área têm apontado para a importância de direcionar atenção não apenas para a própria criança com necessidades especiais, mas também para os diferentes membros da família. Além disso, observa-se que as demandas apresentadas por ter em seu grupo familiar um membro com necessidades especiais podem estar relacionadas com os papéis desenvolvidos por cada membro do grupo (GLAT; DUQUE, 2003; MATSUKURA; FERNANDES, 2006; MATSUKURA et al., 2007).

A literatura internacional apresenta alguns estudos intergeracionais em famílias de crianças com necessidades especiais (GARDNER; SCHERMAN, 1994; HASTINGS; THOMAS; DELWICHE, 2002; MIRFIN-VEITCH; BRAY; WATSON, 1997; MITCHELL, 2007; RAVINDRAN; REMPEL, 2010). Mirfin-Veitch, Bray e Watson (1997), em um estudo que envolveu 12 pares de pais-avós de famílias de crianças com necessidades especiais, apontam que a maneira como os avós reagem à necessidade especial do neto influencia tanto os pais quanto os demais membros da família. Além disso, os autores destacam que os avós exercem um papel de suporte às famílias de crianças com necessidades especiais, a depender de fatores como o sentimento de pertencimento desses avós à família e o tipo de relacionamento e comunicação que eles já mantinham com os familiares no período precedente ao nascimento do neto com deficiência (MIRFIN-VEITCH; BRAY; WATSON, 1997).

Sobre o relacionamento entre avós e irmãos de crianças com necessidades especiais, Ravindran e Rempel (2010) revelaram que esses avós assumem periódica e frequentemente as responsabilidades paternais com os cuidados da rotina diária e com as necessidades de brincar e divertir os irmãos dessas crianças, pois, segundo eles, os pais encontram-se frequentemente ocupados com os cuidados do filho doente, o que os impossibilita de atender às necessidades do outro filho.

\footnotetext{
${ }^{4}$ Foi definida pela portaria 2.344 de 3 de novembro de 2010 da Secretaria de Direitos Humanos da Presidência da República (BRASIL, 2010) a atualização da nomenclatura "pessoa portadora de deficiência" para o termo "pessoa com deficiência". Entretanto, o presente estudo também usará "pessoas com necessidades especiais” por este termo constar em vários artigos recentes da área, assim optou-se pela manutenção do termo como observado no original e, também, por não ser considerado errôneo.
} 
A literatura aponta ainda para a necessidade de novas pesquisas e estudos que aprofundem a compreensão das relaçóes entre avós e pais de crianças com necessidades especiais, especificamente acerca da influência do suporte prestado pelos avós quanto à facilitação ou prejuízos na adaptaçáo parental, bem como no estresse e bem estar dos pais (HASTINGS; THOMAS; DELWICHE, 2002; MITCHELL, 2007).

Em consonância com tais indicativos, o presente estudo buscou aprofundar o conhecimento acerca dos tipos de suporte prestados pelos avós às famílias de crianças com necessidades especiais, bem como dos fatores que influenciam tal suporte e a relação que este desempenha na vida do irmáo da criança com necessidades especiais.

Ressalta-se também que, embora a literatura internacional traga contribuiçóes significativas para a compreensão da realidade de famílias de crianças com necessidades especiais, há de se destacar que diferenças socioculturais certamente necessitam ser consideradas e, nesta direção, estudos brasileiros focalizando essa temática são necessários.

Dessa forma, o presente estudo teve como objetivo investigar o relacionamento intergeracional, as demandas e práticas de apoio presentes no cotidiano de famílias de crianças com necessidades especiais sob a ótica de três geraçóes: avós, mães e irmáos mais velhos de crianças com deficiência.

\section{Método}

\subsection{PARTICIPANTES}

Foram participantes do estudo cinco mães, cinco avós e cinco irmãos de crianças com necessidades especiais.

A idade das mães participantes variou de 31 a 44 anos, todas elas residiam com os pais das crianças e com dois filhos, a criança mais velha, participante do estudo, e o filho com necessidades especiais.

Os irmãos participantes do estudo foram os filhos mais velhos do casal, os quais tinham apenas um irmão mais novo (criança com deficiência). Verificou-se que a idade dessas crianças variou de nove a 14 anos (média de 12,4 anos), enquanto que os filhos com necessidades especiais tinham em média 5,4 anos.

As avós participantes residiam na mesma cidade que a família e apresentaram idade média de 60,8 anos.

Os filhos com necessidades especiais apresentaram diagnósticos de síndrome de Apert, agenesia do corpo caloso, mielomeningocele e hidrocefalia, atraso no desenvolvimento neuropsicomotor e paralisia cerebral. Todas essas crianças estavam em atendimento de fisioterapia e/ou terapia ocupacional na unidade de saúde pesquisada.

\subsection{INSTRUMENTOS DE MEDIDA}

\subsubsection{Roteiros de ENTREVISTAS SEMIESTRUTURADAS}

Foram elaborados três roteiros de entrevistas semiestruturadas, destinados às mães, às avós e aos irmãos das crianças com necessidades especiais participantes do estudo. 
$\mathrm{O}$ roteiro de entrevista destinado às mães focalizou três grandes temas, o primeiro referente à própria mãe, o segundo referente aos seus filhos, e o último referente à avó participante do estudo. O roteiro de entrevista utilizado junto às avós também abordou três grandes temas, o primeiro referente à própria avó, o segundo referente à mãe dos seus netos (sua filha ou nora) e, o último, referente aos seus netos. Já o roteiro de entrevista destinado aos irmãos de crianças com necessidades especiais contemplou quatro grandes temas referentes: a) à própria criança; b) à avó participante do estudo; c) à mãe e; d) ao irmão com necessidades especiais.

Em cada um dos roteiros, as perguntas buscaram abordar aspectos relativos ao convívio familiar, percepçóes e cotidiano de relacionamento familiar como: impacto quando do nascimento da criança com deficiência, consideraçóes acerca do apoio fornecido à família após o nascimento da criança e nos dias atuais, suporte direto e indireto recebido e demandado, perspectivas em relação ao futuro, dentre outros.

\subsection{LOCAL}

O estudo foi realizado em uma cidade de médio porte do interior do estado de São Paulo, com população aproximada de 212.956 habitantes (IBGE, 2009).

A coleta de dados foi feita em uma Clínica Escola vinculada a uma Instituição Federal de Ensino Superior e nas residências de alguns participantes, de acordo com a preferência dos mesmos.

\subsection{ANÁLISE DOS DADOS}

As entrevistas semiestruturadas foram analisadas utilizando-se a técnica do Discurso do Sujeito Coletivo - DSC (LEFÈVRE; LEFÈVRE, 2001, 2005, 2010). Tal técnica vem sendo desenvolvida para pesquisas de representaçáo social desde o final da década de 1990 e utilizada em diversos estudos nacionais e internacionais nas áreas de saúde, educação e outras (BYDLOWSKI; LEFÈVRE; PEREIRA, 2011; CASTRO et al., 2011; LEFÈVRE; LEFÈVRE, 2006; LEFÈVRE et al., 2003; MATSUKURA; CID, 2004).

O método prevê que, por meio de um único discurso, a opinião de uma coletividade seja exposta sem, no entanto, descaracterizar a natureza qualitativa de cada depoimento analisado e reunido para composição desse discurso coletivo. Dessa forma, busca-se recuperar, por meio da opinião dos indivíduos participantes, os atributos da dimensão coletiva contidos em cada fala (LEFÈVRE; LEFÈVRE, 2001, 2005, 2010).

Após todos os depoimentos serem coletados, faz-se a "reunião em discursos-síntese dos conteúdos e argumentos que conformam essas opiniōes semelhantes" (LEFÈVRE; LEFÈVRE, 2010, p. 17). A técnica consiste em uma série de operações sobre os discursos coletados a fim de elaborar depoimentos coletivos a partir de estratos literais significativos, de sentido semelhante, dos diferentes discursos relatados.

Assim, cada DSC elaborado a partir da técnica ilustra uma determinada opiniāo da população estudada, que busca descrever de forma mais clara uma dada representação social ao representá-la por meio da reunião de discursos individuais. Dessa forma, tal método permite 
a elaboração de vários DSCs de acordo com a diversidade de opinião da população pesquisada (LEFÈVRE; LEFÈVRE, 2001, 2005, 2010).

Para a elaboração dos DSCs são utilizadas quatro figuras metodológicas, a saber: expressão chave (ECH), ideia central (IC), ancoragem (AC) e discurso do sujeito coletivo (DSC) (LEFÈVRE; LEFÈVRE, 2010). Dessa forma, os dados obtidos no presente estudo foram analisados por meio das transcriçóes na íntegra das entrevistas, que tiveram seu conteúdo agrupado e categorizado a partir da identificação das expressóes chave e ideias centrais, construindo, assim, discursos comuns representativos de cada grupo (avós, mães e filhos/netos mais velhos), considerando os objetivos que foram propostos.

\section{RRESULTADOS E DiscuSSÁo}

Serão apresentados a seguir os principais resultados do estudo. Inicialmente, buscarse-á discutir a partir dos discursos do sujeito coletivo gerados pelas respostas das avós. Em seguida, discutir-se-á os resultados advindos dos discursos do sujeito coletivo gerados pelas respostas dos irmáos de crianças com necessidades especiais participantes do estudo. Vale ressaltar que se optou por apresentar as discussóes provenientes dos discursos das mães correlacionando-as com as discussóes dos discursos das avós e dos netos, e não individualmente.

\subsection{As Avós}

Incorporadas às suas atividades cotidianas, as avós do presente estudo relataram que a ajuda e o apoio que oferecem à família do neto com necessidades especiais é uma prática presente em seu dia a dia, evidenciando assim a participação na realidade da família da criança com necessidades especiais.

Com relação a esta condição de se ter na família um neto com necessidades especiais, foi apontado por Gardner e Scherman (1994) que, na descoberta das necessidades especiais da criança, os avós vivenciam sentimentos semelhantes aos dos pais, como estresse, tristeza, dentre outros. Esses sentimentos podem ser exacerbados, uma vez que os avós têm pouco acesso à informação. Além disso, os autores observam também que tais sentimentos causam um impacto emocional e estrutural ao trazer desafios e redefinições do papel do ser avô. Além desses achados, a pesquisa indicou que os avós têm um potencial de servir como agentes terapêuticos para seus netos, exercendo uma influência positiva em suas vidas. Em consonância com tais achados, o presente estudo evidencia, por meio do DSC das mães e do DSC das avós, sentimentos desse tipo vivenciados pela terceira geração da família nessa fase de descoberta.

É a gente sofreu bastante né e ela sofreu junto também né porque é avó e a preocupação era igual a nossa né, se ia ficar boa, se não ia, se ia andar, se não ia... (Trecho do DSC das mães referente à questão: "Como era a sua comunicação/ relacionamento com a avó de seus filhos antes do nascimento de seu filho com necessidades especiais?")

No começo foi muito triste viu... chorei tanto, mas rezei tanto, nossa... pedi tanto pra Deus que me desse esse neto curado não foi fácil não viu, sofri demais... eu chorava. Eu fiquei muito triste e preocupada, eu penso tanto que às vezes quase de noite eu nem durmo. (Trecho do DSC das avós referente à questâo: "Quais foram os seus sentimentos quando você ficou sabendo da necessidade especial (dificuldades) de seu neto?"). 
Tais achados, relativos aos sentimentos das avós no momento da descoberta da deficiência do neto, revelam ainda a dupla preocupação vivenciada por elas, através da qual se pode notar a apreensão pelo seu próprio filho (o pai/mãe da criança) e também pelo neto com deficiência, como pode ser observado no discurso a seguir.

Ih foi muito dificil. Porque assim, foi um choque muito grande que a gente recebeu, que ele nascen com aquele problema dele, tudo e eu vi todo o sofrimento dele (neto com necessidades especiais) né, e da minha filha (mãe) também... (Trecho do DSC das avós referente à questão: "Quais foram os seus sentimentos quando você ficou sabendo da necessidade especial (dificuldades) de seu neto?").

Tais resultados são apoiados por Mirfin-Veitch, Bray e Watson (1997) e Ravindran e Rempel (2010), que discutem sobre a preocupação presente na realidade de avós de crianças com necessidades especiais, preocupação essa que se refere tanto aos pais das crianças como às próprias crianças com deficiência.

O estudo realizado por Ravindran e Rempel (2010) revela ainda que a dupla preocupação pode transformar-se em tripla, uma vez que os avós tomam para si também o papel de cuidarem dos irmãos dessas crianças. Tal preocupação com o neto, irmão da criança com necessidades especiais, também foi observada no presente estudo, quando as avós evidenciaram a preocupação com que tratam o neto mais velho na tentativa de suprir-lhe demandas de atenção, afeto e carinho.

Porque eu dou muito carinho pra ele, entendeu? Eu faço dele a parte mais importante. (Trecho do DSC das avós referente à questão: Você acredita que a sua maneira de enfrentar essa notícia ajudou ou atrapalhou os seus outros netos? De que forma?).

Acerca do relacionamento entre avós e netos com desenvolvimento típico, as avós e os netos mais velhos revelaram que possuem um relacionamento de afeto, respeito e ajuda. Tal resultado se assemelha aos relatos da literatura, que indicam que há uma influência benéfica e recíproca no desenvolvimento de netos e avós no que tange ao seu relacionamento (ARAÚJO; DIAS, 2002).

Entretanto, observa-se que o relacionamento entre avós e netos, irmãos de crianças com necessidades especiais, pode se configurar de maneira mais ampla e apresentar especificidades, uma vez que esses avós frequentemente assumem para si não apenas as responsabilidades e preocupaçóes advindas do "ser avô", mas também aquelas recebidas com as dificuldades de tempo ou sobrecarga dos pais da criança devido aos cuidados extras que o filho com necessidades especiais pode gerar (RAVINDRAN; REMPEL, 2010). Nesse sentido, os discursos das avós do presente estudo, revelaram que o relacionamento que essas mantêm com seus netos com desenvolvimento típico, irmãos de crianças com necessidades especiais, é permeado por preocupaçóes.

Ah é normal eu amo muito ele também, às vezes eu falo pra ele que tem que ajudar a mamãe quando ela precisa né, porque ele é o braço direito aqui, quando a gente trabalha, é ele né... mas o duro é que eu me preocupo também com o estudo dele, ainda eu falei pra ela (mäe) pra ela não sobrecarregar muito ele, pra ele poder estudar mais, não se envolver muito né porque ai atrapalha os estudos. (Trecho do DSC das avós referente à questáo: "Como é o seu relacionamento com seu neto mais velho?"). 
Já sobre o relacionamento com o neto com necessidades especiais, as avós revelaram que, além do afeto, há também um compartilhamento de aprendizados:

... o meu relacionamento com ele, de mim pra ele, é excelente, eu entendo todas as necessidades dele, eu procuro fazer coisas diferentes, brincar, levo ele no parque e tudo. Mas também fico brava na hora que tem que ficar, entende? O meu relacionamento com ele eu acho que tá sendo muito bom, pra mim também, sabe? Eu to aprendendo com ele né, porque a gente tá ensinando, mas também tá aprendendo com os problemas né... (Trecho do DSC das avós referente à questáo: "Como é o seu relacionamento com seu neto com necessidades especiais?”).

Além disso, quando questionadas acerca dos tipos de ajuda que oferecem aos netos com deficiência, as avós relataram oferecer apoios semelhantes àqueles ofertados aos netos com desenvolvimento típico, como dar carinho e brincar, e apoios específicos à realidade da criança com deficiência, como ajudá-la a engatinhar ou ensinar a andar.

Com relação à ajuda ofertada pelas avós aos netos e à família, as avós relataram sobre o suporte emocional e instrumental que oferecem, sendo que tais apoios apresentam características específicas relacionadas ao fato de se ter na família um membro com necessidades especiais, como pode ser ilustrado a seguir, no DSC dos irmãos das crianças com deficiência.

Ajuda. Ela sempre tá vindo aqui, cuidando, conversando com a gente, cuidando de mim e do D. (criança com necessidades especiais), quando minha mãe não tá e deixa aqui as coisas pra quando ela chegar, ai minha avó faz pra ela. Lavar a louça, limpar minha casa, ajudando a minha mãe na casa, a cuidar do D. (DSC dos irmãos referente à questão: "Sua avó ajuda sua família? Como?").

Observa-se que no presente estudo as avós referiram conferir à família do neto com necessidades especiais apoio instrumental e emocional, sendo que tal apoio foi também claramente reconhecido pelas mães e netos quando questionados sobre isso.

Assim, os resultados encontrados estão em consonância com a literatura, a qual aponta que os diferentes tipos de ajuda, oferecidos pelos avós de crianças com deficiência às famílias, sejam eles instrumental ou emocional, apresentam-se como importante fonte de apoio às famílias (GARDNER; SCHERMAN, 1994; HASTINGS; THOMAS; DELWICHE, 2002; MIRFIN-VEITCH; BRAY; WATSON, 1997; MITCHELL, 2007; RAVINDRAN; REMPEL, 2010).

No entanto, o suporte social advindo dos avós algumas vezes também tem sido relatado na literatura como fonte de estresse para os pais de crianças com necessidades especiais (HASTINGS; THOMAS; DELWICHE, 2002; MITCHELL, 2007). Este fato também foi observado no presente estudo, uma vez que as mães relataram que a ajuda oferecida pelas avós não diminui o seu estresse ou que, às vezes, essa ajuda é fonte de estresse, como se observa no DSC das mães apresentado a seguir.

Não diminui o meu estresse porque ela é muito de idade e a gente fica mais preocupada né, então seria três crianças numa casa. Até às vezes eu penso assim, mais ou menos, porque tem horas que a gente discute porque eu quero que ela faz de um jeito ela foi e fez do outro, eu náo gosto que mude as minhas coisas de lugar, ela muda então tem hora que ela mais me estressa do que desestressa. (DSC das mães referente à questão: "Você acha que a ajuda prestada pela avó de seus filhos diminui o seu estresse?"). 
Não obstante, ainda que o apoio das avós às famílias seja reconhecido e presente no dia a dia de todos os envolvidos, os resultados revelaram que, na percepção das próprias avós sobre se sua ajuda às famílias é suficiente, as mesmas apontaram que gostariam de ajudar ainda mais, porém não o fazem devido às limitaçóes financeiras, ou por questóes de saúde relacionadas à idade.

Entretanto, ainda que as avós do presente estudo tenham revelado acreditar que a ajuda oferecida por elas às suas famílias não seja suficiente, observou-se que elas frequentemente deixam de lado seus interesses, ou coisas particulares, em prol de ajudar a família do neto com necessidades especiais. Isso demonstra o importante esforço desempenhado pelas avós para ajudarem suas famílias.

Às vezes eu deixo o serviço pra fazer, pra servir de companhia pra ele (neto com necessidades especiais), tem hora que a mãe dele sai e deixa ele aqui comigo e eu fico brincando aqui com ele. Eu fico às vezes até seis, sete horas da noite... pra dormir lá com o mais velho porque o D. (criança com necessidades especiais) ficou internado na UTI. Então eu deixo de fazer as minhas coisas, que nem agora mesmo né eu to lotada de serviço na minha casa e to aqui... porque eu trabalho todo dia né, se eu não precisasse trabalhar eu vinha mais pra cá, até eu aposentar tem que ficar nessa situação, por isso que eu fico nervosa. (DSC das avós referente à questão: "Você deixa de fazer algumas coisas particulares ou deixa de lado alguns interesses próprios para poder ajudar seu neto com necessidades especiais?”).

Assim, observa-se que os achados deste estudo estão em consonância com os resultados encontrados por Mirfin-Veitch, Bray e Watson (1997), que revelaram que os avós de famílias de crianças com deficiência interpretam seus papéis de avós de uma maneira bastante tradicional, o que faz com que a obrigação para com a família preceda outras responsabilidades. Os autores indicam ainda que os avós participantes do estudo também não acreditavam que a ajuda fornecida por eles às famílias fosse marcante, o que também foi apontado pelas avós participantes do presente estudo.

\subsection{OS IRMÁOS}

Quando questionados acerca das responsabilidades que tinham em suas casas, os irmãos relataram, além das responsabilidades que podem ser comuns as outras crianças, algumas outras que são especificas da realidade de se ter um irmão com necessidades especiais, como pode ser observado nos DSCs seguintes.

\footnotetext{
Arrumar meu quarto. (DSC dos irmãos referente à questáo: "Você tem alguma responsabilidade em casa?").

Ajudo a olhar meu irmão (criança com necessidades especiais), eu to sempre ajudando, eu cuido do meu irmão e ajudo minha máe. (DSC dos irmãos referente à questão: "Você tem alguma responsabilidade em casa?").
}

Soares, Franco e Carvalho (2009) apontaram que as responsabilidades de cuidado da criança com deficiência não são exclusivamente dos irmãos, entretanto a ajuda prestada por eles é reconhecida como necessária e importante para as mães. Tal observação é apoiada pelos resultados do presente estudo, como se verifica no discurso a seguir. 
... ajuda e muito, se eu preciso sair ele que fica com o D. (filho com necessidades especiais) ele que troca, ele que dá as coisas pra ele comer, ele que brinca, então bem dizer quando ele tá em casa é mais ele que cuida do que eu... (Trecho do DSC das mães referente à questão: "O seu filho mais velho ajuda você a cuidar do irmão com necessidades especiais? Que tipo de ajuda é essa?”).

Sobre o relacionamento entre mães e filhos, os irmãos de crianças com necessidades especiais participantes do estudo disseram relacionar-se positivamente com suas mães, sem remeter a esse relacionamento o fato de terem um irmáo com deficiência. Entretanto, suas mães, ao discorrerem acerca do relacionamento que mantém com o filho mais velho, citaram, com frequência, o filho com deficiência e destacaram a falta de atenção e tempo despendido ao filho mais velho devido às demandas geradas com o nascimento do filho com necessidades especiais, como se observa a seguir.

...ele é uma criança muito compreensiva né, porque, quando o D. (criança com necessidades especiais) nasceu ele pegou uma responsabilidade que não era dele, eu deixei um pouco ele de lado sabe. Nossa relaçâo é boa, assim apesar de assim, depois do D. eu acabei deixando um pouco mais pra... dar a atenção que ele precisa mesmo, mas a gente conversa bem eu falo pra ele que o que ele precisar pra ele falar pra mim né, mas eu acho que ele até entende assim, um pouco o lado do irmäo, mas a gente se dá muito bem. (Trechos do DSC das mães referente à questão: "Como é o seu relacionamento com seu filho mais velho?").

Esta realidade citada pelas mães, relativa à atenção e ao tempo que são concedidos aos filhos mais velhos, também surgiu no discurso dos irmãos participantes do presente estudo, uma vez que os mesmos relataram que gostariam de receber mais atenção por parte das mães, pelo fato delas dedicarem mais atenção e cuidado ao irmão com necessidades especiais, além de apontarem sobre as mudanças em suas vidas e na vida de suas famílias com o nascimento do irmão.

Ah eu tenho menos atenção, que com o nascimento dele meu pai mudou e minha mãe também. Ah que eles dão mais atenção pro meu irmão agora, então mudou que antes eu tinha mais atenção, eu não fico mais tanto tempo com a minha mãe, com o meu pai. (DSC dos irmáos referente à questáo:

“Com o nascimento do seu irmão com necessidades especiais o que mudou em sua vida?”).

Tal achado se assemelha ao resultado encontrado por Matsukura e Cid (2008), no qual irmãos de crianças com necessidades especiais expressaram por meio de atividades o desejo de passarem mais tempo com suas mães. As autoras refletem ainda sobre a realidade dessas mães, que, devido às altas demandas de cuidado que os filhos com necessidades especiais requerem, sentem dificuldade de reservar um tempo específico ao cuidado do filho com desenvolvimento típico.

Ainda, destacando as formas de enfrentamento desta realidade, alguns irmãos do presente estudo relataram que não gostariam de receber mais atenção por parte das mães, por acreditarem que os irmãos com necessidades especiais precisem mais, como pode ser observado no DSC seguinte.

"Ah não porque como o D. (irmão com necessidades especiais) tem problema, ele precisa mais do que eu né." (DSC dos irmáos referente à questão: "Você gostaria de receber mais atenção/ tempo dos membros de sua família? De quem?") 
O que se observa é que estes irmãos apresentam características de altruísmo e autocrítica, uma vez que não verbalizam o desejo por maior quantidade de atenção pelo fato de perceberem as altas demandas provenientes do cuidado do irmão com necessidades especiais. Nessa direção, Núñes (2003) cita características presentes nos irmãos de crianças com deficiência, como excesso de responsabilidades, busca por maturidade e competência e renúncia da própria vida na tentativa de recompensar os pais por toda dor e sacrifícios com o outro irmáo. Os achados do presente estudo reforçam tais consideraçóes.

Outro dado obtido, que também parece específico da realidade vivenciada pelas famílias de crianças com necessidades especiais diz respeito às principais dificuldades vivenciadas pelos irmãos dessas crianças. Segundo o DSC obtido, as crianças atribuíram as suas maiores dificuldades ao fato de não poderem ajudar mais suas mães, como se observa a seguir.

É que eu agora não posso ajudar tanto minha mãe porque agora eu já tenho mais lição de casa, tenho que cuidar do meu irmão (criança com necessidades especiais), aí..." (DSC dos irmãos referente à questão: "Quais são as suas principais dificuldades hoje?")

A literatura aponta que tais sentimentos podem ser característicos de irmãos de crianças com necessidades especiais e refletem a influência que esta realidade tem sobre elas (FIAMENGHI; MESSA, 2007; GOMES; BOSA, 2004; MATSUKURA; CID, 2008; NUNES; SILVA; AIELLO, 2008).

Destarte, o que se observa no presente estudo é que tanto as avós quanto os irmãos das crianças com deficiência demonstraram sentimentos semelhantes com relação à ajuda oferecida às mães, revelando o desejo de prestar um apoio ainda maior do que o exercido no contexto familiar. Assim, o presente estudo tece a hipótese de que os membros de ambas as geraçóes sentem-se responsáveis pelo fornecimento de ajuda à família da criança com necessidades especiais.

Acerca do relacionamento dos irmãos (netos mais velhos) com suas avós, ao falarem sobre o que gostam de fazer com as mesmas, as crianças revelaram a relação de proximidade que mantêm com suas avós ao relatarem que compartilham com elas atividades como, por exemplo, passar um tempo juntos, fazer compras ou cozinhar. Tais atividades são semelhantes às apontadas pela literatura como compartilhadas entre avós e netos que não têm irmãos com necessidades especiais (DIAS; SILVA, 2003). Entretanto, também foi possível observar práticas de interação mais específicas da realidade dessas famílias, uma vez que, além das atividades já citadas, os netos relataram também atividades de cuidado do irmão com necessidades especiais com as avós.

Eu faço bastante coisa com ela, quando eu vou na casa dela eu ajudo ela, eu vou sempre no supermercado com ela, cuido do D. (criança com necessidades especiais), quando eu vou lá, ou ela vem aqui ai a gente cuida do D. (Trecho do DSC dos irmãos referente à questáo: "O que você e sua avó $\underline{\mathrm{A}}$ (avó participante) fazem juntos? Dê exemplos.").

Assim, o presente estudo ressalta que, além de atividades usuais compartilhadas entre avós e netos (com desenvolvimento típico), a presença de um membro com necessidades especiais na família faz com que eles compartilhem atividades específicas desta realidade. 
Com relação às possíveis mudanças de conduta das avós para com seus netos, após o nascimento do neto com deficiência, as avós participantes reportaram não terem mudado com seus netos mais velhos (com desenvolvimento típico) ou terem se aproximado mais deles após o nascimento do irmão, na tentativa de suprir-lhes demandas de afeto e atenção por perceberem as demandas extras que os netos com deficiência geravam aos pais, fato que prejudicava a quantidade e qualidade de atenção conferida por eles aos filhos mais velhos.

Diferentemente, no estudo de Gardner e Scherman (1994), os avós relataram não apresentar nenhuma mudança para com os netos sem deficiência, embora ressaltassem a consciência de um potencial impacto negativo nesse relacionamento, uma vez que o neto com deficiência requer cuidados extras que conflitam com a convicção de que os outros netos devem ser tratados igualmente.

Eu procuro dar ainda mais atenção pra ele (neto mais velha). (Trecho do DSC das avós referente à questáo: "Você acha que a sua conduta com seus netos mudou após o nascimento de seu neto com necessidades especiais?")

Eu dou mais atenção pra ele (neto mais velha) porque ele não pode se sentir rejeitado porque o irmão é doente, então você tem que... eu sempre brinco mais com ele... eu dou mais atenção pra ele... (Trechos do DSC das avós referente à questão: "Você acha que você trata seus netos da mesma forma com que trata seu neto com necessidades especiais? Se não, em quais aspectos você nota a diferença?”)

Sobre o tema, os netos entrevistados pelo presente estudo reportaram mudanças em seu relacionamento com a avó e indicaram o nascimento do irmão com necessidades especiais como motivo disparador, como se observa no DSC das crianças.

\footnotetext{
Ah a gente se encontra mais... mudou por causa do D. (criança com necessidades especiais), quando ele nasceu. Agora minha mãe tem que sair, eu e ele fica lá com a vó ai nós fica brincando também, porque agora tem que cuidar do D. é, tem que cuidar do meu irmáo (criança com necessidades especiais). (DSC dos irmãos referente à questão: "Você se lembra como era o seu relacionamento

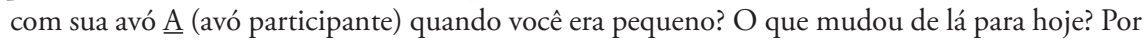
que você acha que mudou?")
}

Observa-se que as crianças remeteram ao nascimento do irmão com necessidades especiais o fato de seu relacionamento com a avó ter mudado, uma vez que agora elas se veem com maior frequência devido às necessidades de cuidado do irmão. Essa mudança parece ser positiva sob a óptica dos netos e das avós. Nota-se ainda que, ao falarem sobre as avós, as crianças demonstraram a importante fonte de apoio emocional e de afeto que as mesmas representam para elas, ao dizerem, por exemplo, que sempre foram cuidadas e que ainda recebem cuidados das avós.

Dessa forma, hipotetiza-se que, na falta de tempo das mães, as avós desempenham o importante papel de suprir as demandas emocionais e de cuidado dos irmãos de crianças com necessidades especiais, como também apontado por Ravindran e Rempel (2010), em um estudo realizado com avós de crianças com doenças crônicas.

As avós do presente estudo ainda desempenham outro importante papel na vida de seus netos com desenvolvimento típico à medida que acabam por intermediar a relação entre eles e seus pais, como se observa no DSC a seguir. 
"Acho que sim, quando eu brigo com a minha mäe ela conversa comigo, por exemplo, quando eu não faço coisa errada e minha mãe acha que eu faço aí minha avó não deixa minha mãe me bater, ou quando eu fico bravo com a minha mãe e com o meu pai ela fala pra eu não ficar triste." (DSC dos irmãos referente à questáo: "Você acha que sua avó compreende você? Dê exemplos.").

Tal resultado se assemelha com o apontado pela literatura internacional, a qual revela que os avós de famílias de crianças com necessidades especiais frequentemente agem de modo a intermediar e favorecer as relaçóes entre pais e filhos com desenvolvimento típico (RAVINDRAN; REMPEL, 2010).

Destarte, o presente estudo aponta para a necessidade e adequação de açóes de saúde e educação voltadas aos pais, avós e irmãos de crianças com deficiência, uma vez que a vivência das consequências e impactos advindos do nascimento de uma criança com necessidades especiais interfere no cotidiano familiar e individual, bem como nos relacionamentos familiares.

\section{ConsideraçóEs FINAIS}

O presente estudo respondeu aos objetivos propostos ao aprofundar o conhecimento acerca do relacionamento intergeracional presente em famílias de crianças com necessidades especiais, bem como ao ampliar a compreensão das características desses relacionamentos e das trocas de apoio estabelecidas principalmente entre avós e netos mais velhos, irmãos de crianças com necessidades especiais, frente às demandas de cuidado, atenção e alteraçóes de rotina e cotidiano enfrentadas pelas famílias destas crianças.

Verificou-se, ainda, que avós e netos (com desenvolvimento típico) representam uma importante rede de apoio para as famílias e apontam para um relacionamento intergeracional positivo, que parece proporcionar fonte de apoio para ambos à medida que, ao se relacionarem, proporcionam cuidados e atenção capazes de minimizar a possível ausência das máes devido às intensas demandas de cuidado do filho com necessidades especiais.

Aponta-se que o estudo apresenta limitações no que se refere ao pequeno número de participantes envolvidos. Além disso, as deficiências das crianças, embora todas se caracterizassem por acarretarem disfunçóes físicas ao desenvolvimento das mesmas, foram de tipos variados, o que pode acarretar em diferenças nas demandas de cuidado e de arranjos cotidianos. Tais diferenças podem ser melhor focalizadas em estudos que considerem essa variável na composição da amostra de participantes.

Nessa direção, reafirma-se a adequação da opção da utilização da técnica do Discurso do Sujeito Coletivo para a análise dos dados obtidos, onde se pretende a identificação das representaçôes sociais do grupo focalizado e se aponta que um maior e diverso número de participantes seria desejado, pois ampliaria tal identificação.

Assim, o estudo aponta para a necessidade de continuidade de investigação sobre o tema e para a importância de direcionar maior atenção a esses membros da família, uma vez que a realidade de se ter na família um membro com deficiência pode gerar necessidades de informação acerca dos cuidados necessários despendidos à criança e dos sentimentos vivenciados por diferentes geraçóes frente à realidade e ao contexto familiar. 


\section{REFERÊNCIAS}

ARAÚJO, M.R.G.L.; DIAS, C.M.S.B. Papel dos avós: apoio oferecido aos netos antes e após situações de separação/divórcio dos pais. Estudos de psicologia, Natal, v. 7, n. 1, p. 91-101, 2002.

BRASIL, Secretaria de Direitos Humanos. Portaria número 2.344, de 3 de novembro de 2010.

Disponível em: < http://portal.mj.gov.br/conade/> Acesso em: maio 2010.

BYDLOWSKI, C.R.; LEFEVRE, A.M.C.; PEREIRA, I.M.T.B. Promoção da saúde e a formação cidadã: a percepção do professor sobre cidadania. Ciênc. saúde coletiva, Rio de Janeiro, v. 16, n. 3, p. 1771-1780, 2011.

CASTRO, S.S. et al. Acessibilidade aos serviços de saúde por pessoas com deficiência. Rev. Saúde Pública, São Paulo, v. 45, n. 1, p. 99-105, 2011.

DIAS, C.M.S.B.; SILVA, M.A.S. Os avós na perspectiva de jovens universitários. Psicologia em Estudo, Maringá, v. 8, n. esp., p. 55-62, 2003.

FIAMENGHI, G.A.; MESSA, A.A. Pais, filhos e deficiência: estudos sobre as relaçôes familiares. Psicologia: ciência e profissão, Brasília, v. 27, n. 2, p. 236-245, 2007.

GARDNER, J.E.; SCHERMAN, A. Grandparents' beliefs regarding their role and relationship with special needs grandchildren, Education \& Treatment of Children, v. 17, n. 2, p. 185-196, 1994.

Disponível em: http://link.periodicos.capes.gov.br/sfxlcl3?url_ver=Z39.88-2004\&url_ctx_fmt=infofi/ fmt:kev:mtx:ctx\&ctx_enc=info:ofi/enc:UTF-8\&ctx_ver=Z39.88-2004\&rfr_id=info:sid/sfxit. com:azlist\&sfx.ignore_date_threshold=1\&rft.object_id=960238588213\&svc.fulltext=yes Acesso em: mar/2010.

GLAT, R.; DUQUE, M.A.F.T. Convivendo com filhos especiais: o olhar paterno. Rio de Janeiro: Sette Letras, 2003.

GOMES, V.F.; BOSA, C. Estresse e relaçóes familiares na perspectiva de irmãos de indivíduos com Transtornos Globais do Desenvolvimento. Estudos De Psicologia, Natal, v. 9, n. 3, p. 553-561, 2004. HASTINGS, R.P.; THOMAS, H.; DELWICHE, N. Grandparent support for families of children with down's syndrome, Journal of applial research in intellectual disabilities, v. 15, n. 1, p. 97-104, 2002. Disponível em: http://onlinelibrary.wiley.com/doi/10.1046/j.1360-2322.2001.00097.x/full Acesso em: mar/2010.

Instituto Brasileiro de Geografia e Estatística (IBGE). Disponível em: <http://www.ibge.com.br/ cidadesat/default.php> Acesso em: maio/2010.

LEFÈVRE, F.; LEFÈVRE, A.M.C. Pesquisa de representação social: um enfoque qualiquantitativo: a metodologia do discurso de sujeito coletivo. Brasília: Líber livro, 2010.

LEFÈVRE, F.; LEFÈVRE, A.M.C. O sujeito coletivo que fala. Interface, Botucatu, v. 10, n. 20, p. 517-524, 2006.

LEFÈVRE, F.; LEFÈVRE, A.M.C. $O$ discurso do sujeito coletivo. Um novo enfoque em pesquisa qualitativa. Caxias do Sul: Ed. Universidade de Caxias do Sul, 2005.

LEFÈVRE, F.; LEFÈVRE, A.M.C. O discurso do sujeito coletivo: uma nova abordagem metodológica em pesquisa qualitativa. Caxias do Sul: Ed. Universidade de Caxias do Sul, 2001.

LEFÈVRE, F. et al. Medicamentos de venda sem prescrição médica. O Discurso do Sujeito Coletivo Idoso Hipertenso. Acta Farmaceutica Bonaerense, Buenos Aires, v. 22, n. 1, p. 65-71, 2003.

MATSUKURA, T.S, CID, M.F.B. Irmãos de crianças com necessidades especiais: Buscando conhecer a realidade do outro. Revista Brasileira de Educação Especial, Marília, v. 10, n. 3, p. 355-370, 2004. 
MATSUKURA, T.S.; CID, M.F.B. Irmãos de crianças com necessidades especiais e suas famílias: diferentes expressóes sobre essa realidade. Cadernos de Terapia Ocupacional da UFSCar, São Carlos, v. 16, n. 1, p. 7-16, 2008.

MATSUKURA, T.S.; FERNANDES, Q.B. Famílias de crianças com necessidades especiais: identificando açôes de intervenção e percepçóes dos profissionais da equipe multiprofissional. Temas sobre Desenvolvimento, Sáo Paulo, v. 15, n. 87-88, p. 30-34, 2006.

MATSUKURA, T.S. et al. Estresse e suporte social em mães de crianças com necessidades especiais. Revista Brasileira de Educação Especial, Marília, v. 13, n.3, p. 415-428, 2007.

MINUCHIN, P.; COLAPINTO, J.; MINUCHIN, S. Trabalhando com famílias pobres. Porto Alegre: Artes Médicas Sul, 1999.

MINUCHIN, S.; FISHMAN, C. Técnicas de terapia familiar. Porto Alegre: Artes Médicas, 1990. MITCHELL, W. Research review: the role of grandparents in intergenerational support for families with disable children: a review of the literature. Child \& Family Social Work, v. 12, n. 1, p. 94-101, 2007. Disponível em: http://onlinelibrary.wiley.com/doi/10.1111/j.1365-2206.2006.00421.x/full Acesso em: mar/2010.

MIRFIN-VEICH, B.; BRAY, A.; WATSON, M. We're just that sort of family: intergenerational relationship in families including children with disabilities. Family Relations, Minneapolis, v. 46, n. 3, p. 305-311, 1997.

NUNES, C.C. Interação entre irmãos de indivíduos com deficiência mental: o papel da idade e do apoio social da família, Dissertação de Mestrado: Universidade Federal de São Carlos, 2006.

NUNES, C.C.; SILVA, N.C.B.; AIELLO, A.L.R. As contribuiçôes do papel do pai e do irmão do indivíduo com necessidades especiais na visão sistêmica da família. Psicologia: Teoria e Pesquisa, Brasília, v. 24, n. 1, p. 37-44, 2008.

NÚNES, L.B. La familia con un hijo con discapacidad: sus conflictos vinculares, Arch. Argent. Pediatr., Buenos Aires, v. 10, n. 2, p. 133-142, 2003.

RAVINDRAN, V.P.; REMPEL, G.R. Grandparents and siblings of children with congenital heart disease. Journal of Advanced Nursing, v. 67, n. 1, p. 169-175, 2010. Disponível em: http:// onlinelibrary.wiley.com/doi/10.1111/j.1365-2648.2010.05482.x/full Acesso em: dez/2010.

REICHMAN, N.E.; CORMAN, H.; NOONAN, K. Impact of child disability on the Family. Maternal and child health journal, v. 12, n. 6, p. 679- 683, 2008. Disponível em: http://www. springerlink.com/content/665707u847134377/ Acesso em: mar/2010.

SILVA, N.L.P.; DESSEN, M.A. Deficiência mental e família: implicaçôes para o desenvolvimento da criança. Psicologia: teoria e pesquisa, Brasília, v. 17, n. 2, p. 133-141, 2001.

SOARES, M.P.G.; FRANCO, A.L.S.; CARVALHO, A.M.A. Crianças que cuidam de irmãos com necessidades especiais. Psicologia: teoria e pesquisa, Brasília, v. 25, n. 1, p. 45-54, 2009.

TURNBULL, A.P.; TURNBULL, H.R. Families, professionals and exceptionality: Collaboration for empowerment. Columbus: Merrill Publishing Company, 2001.

ZAMBERLAN, M.A.T.; BIASOLI-ALVES, Z.M.M. Interaçôes familiares: teoria, pesquisa e subsídios à intervenção. Londrina: Editora da UEL, 1996.

Recebido em: 12/12/2011

Reformulado em: 28/06/2012

Aprovado em: 27/08/2012 